\title{
Influence of Physical Education on Personality Development
}

\author{
Aleksey Yurievich Polyakov \\ Department of Humanities and Socio-Economic Sciences \\ Ufa State Petroleum Technological University, Branch of the University in the City of Oktyabrsky \\ Oktyabrsky, Republic of Bashkortostan, Russia \\ e-mail polykov.74@mail.ru
}

\begin{abstract}
- the article analyzes the influence of physical culture and sports on personality development. It provides evidence that physical education and sports strengthen human health, improve the physical state and have a significant impact on social activity and moral and intellectual qualities of a person. Physical education and sport affect the process of self-cognition and self-improvement, development of will and self-confidence.
\end{abstract}

Keywords - physical education, sport, health, selfimprovement, personality

\section{INTRODUCTION}

Physical education and sports are an integral part of education. They contribute to the development of physical competence and physical fitness and help young have an active lifestyle. Healthy and active youth are likely to be motivated to study, attentive and promising. This is the only program that provides youth with the opportunity to develop motor skills and mental and physical fitness. The benefits of physical activities disease prevention, safety and injury prevention, reduced morbidity and premature mortality, and improved mental health. Physical education is a course which informs young people about benefits of physical activities, skills and knowledge required for safe, satisfying physical activities, provides information on how to interact with other people. Physical culture and sports are an independent type of human activities, they are of high importance for the development of society, have a significant impact on social production, development of social relations, and personality.

Today, physical education and sports are very popular. Many articles, books have been written about sports, performances have been staged, films have been shot, sociologists, physicians, historians, educators and other specialists are studying the problems of sports. This is not a tribute to fashion, but reflects the importance of physical culture and sport in modern society [1]. Physical culture and sport are factors that shape a comprehensively and harmoniously developed personality.

Today, physical education and sports are very popular. Many articles, books have been written about sports, performances have been staged, films have been shot; sociologists, physicians, historians, educators and other specialists are studying the problems of sports. These studies emphasize the importance of physical culture and sports in modern society [1]. Physical culture and sports are factors that shape a comprehensively and harmoniously developed personality.

Physical education is a pedagogical process aimed at developing healthy, physically perfect, socially active generations. Physical education strengthens health, develops physical and spiritual forces, increases working capacity, and prolongs creative longevity. Physical education classes improve the body, develop physical qualities and form motor abilities, skills. Physical exercises affect productivity, intensify creative activities of people. Regular physical education classes increase students' mental performance, improve the depth of thinking, combinatorial abilities, operative, visual and auditory memory, and sensorimotor reactions. Physical education and sports also lower the level of diseases and injuries [2].

Physical education and sports are useful to all people, not just those whose professions involve the use of great physical strength or significant mental efforts. In modern conditions, the person's physical activity decreases, which decreases body's fitness level and reduces mental and physical working capacity and body's resistance to diseases.

\section{MeTHODS AND MATERIALS}

Physical culture and sports are an effective means of physical development, protection and strengthening of health, a reasonable form of organizing and spending leisure time, the sphere of communication. They affect such aspects of human life as authority and position in society, labor activity, moral and intellectual characteristics, aesthetic ideals and value orientations. They impact social production and development of social relations. The society recognizes such activities as useful and necessary for all, creates conditions for their development. Indicators of physical culture are as follows:

- a set of material and spiritual values created for the physical improvement of members of society;

- the level of health and physical development of people;

- the degree of use of physical exercises in education and production fields and in everyday life;

- other purposes of public practice.

Physical education and sports provide extensive opportunities for development, approval and expression. The process of regular and focused physical education or training 
involves the education of various skills, abilities and physical qualities, mental qualities and personality traits.

Physical culture aims at upbringing a harmonious and diversified personality able to realize its strength in a healthy lifestyle, professional work, and creating the required sociocultural comfortable environment.

Currently, physical culture is crucial for an individual and society. This allows identifying new trends in the development of public opinion and personal motivations for the development of physical culture values.

\section{Physical education can}

- develop intellectual abilities, such as the ability to analyze and generalize, explain and transfer knowledge to various fields of culture and scientific disciplines;

- educate different physical qualities, taking into account the methods used, the sequence of development, the healing value of the specific physical load;

- develop a scientific worldview, citizenship, moral and aesthetic qualities, as well as an active attitude to work;

- teach methods of self-education, self-improvement, selfcontrol and correction. Physical education and sports help to educate a comprehensively developed personality. Students improve moral, mental, labor and aesthetic education. Physical culture and sports have a specific effect on a person.

In training sessions, and especially during sports competitions, students receive great physical exertion, developing such qualities as willpower, courage, self-control, determination, self-confidence, endurance, discipline. Exercise and sports are focused fostering a sense of collectivism, dedication to your team [3].

Physical education helps increase mental performance. When mastering modern curricula, students experience significant psychological stress. A high level of physical fitness ensures mental performance for the academic year [4]. For the system "state of the body - optimal physical activity mental disability", the last link directly depends on the first two ones. Untrained students significantly reduce attention and memory. To maintain mental labor ability, continuous physical exercises and sports taking into account the physical condition of each student and regulating training loads that provide a positive emotional background are required.

The labor education is the consistent and systematic development of personality traits that determine the level of preparation for socially useful work, industriousness, a conscious attitude to work. Diligence is fostered by doing physical exercises to overcome fatigue. Purposefulness, perseverance in achieving the goal has a positive effect on work.

Due to physical exercises, the human body develops harmoniously; movements and actions acquire a more refined, energetic, beautiful character [5]. A person receives aesthetic pleasure from classes. The person has a beautiful appearance develops moral and volitional qualities, aesthetics of actions and behavior in society.

\section{RESULTS AND DISCUSSION}

In pedagogy, the concept "principles" reflects regularity of education guiding activities of the teacher [6].

The general principles of physical education include:

- comprehensive and harmonious development of personality; life;

- the relationship of physical education and the practice of

- improving orientation of physical education.

The principle of comprehensive and harmonious development of the personality means:

1) the unity of all aspects of education, development of a harmoniously developed personality. It is necessary to solve problems of moral, aesthetic, physical, mental and labor education. Only then, physical qualities and skills of a person, his sports achievements have a social value and deep content;

2) general physical fitness. With the integrated use of physical culture factors, it is necessary to use vital physical qualities (and motor abilities), forming a fund of motor abilities and skills. Therefore, in specialized forms of physical education, there should be a unity of general and special physical training.

The requirements of general physical training are based on regularity of human development, namely, on the inextricable relationship of systems and organs. Comprehensive physical training is the basis of any activity, it is a source of moral and physical strength [7].

The principle of the relationship of physical education with the practice of personality is the main service function of physical education aimed at preparing people for work and life.

Some scientists believe that the main function of physical education and sports is to reduce stiffness of modern life. However, others believe that physical education should prepare people to work productively and defend their homeland.

This gives the principle a new meaning. To implement this principle, we proceed from the fact that it is necessary to be prepared for work and defense.

According to some scientists, the applied meaning of physical education is development of motor skills required in life. But, if skills can be used for labor or combat activities, physical education is connected with life.

It is necessary that a person can quickly master any skill. Only a strong person can master new skills and technologies.

A person trained for life activities has a high level of development of physical qualities and various motor skills. In total, these factors provide physical fitness for life.

Physical education provides a high level of health for members of society, develops strength, endurance. The principle of the relationship of physical education and life is used to solve particular problems of physical education and 
sports training; therefore, physical exercises have an applied meaning.

Thus, it is possible to formulate specific provisions of the principle of the relationship of physical education with the practice of life:

- it is necessary to choose such physical exercises that develop motor and labor skills;

- it is necessary to train motor abilities and skills, develop physical abilities;

- it is necessary to form an active life position, fostering industriousness, patriotism and moral qualities [8].

The whole system of physical education is imbued with the idea of strengthening human health [9]. The principle of health orientation of physical education consists of the following provisions:

- responsibility for improving health of those involved in physical exercises. Physical education organizations, physical education teachers, trainers deal with healthy people. They are responsible for maintaining health of those involved and strengthening it;

- the unity of medical and pedagogical control. Only proper exercises have a healing effect. Therefore, biological characteristics of age, gender and health status should be taken into account. These features are taken into account by strict systematic medical and pedagogical control [10]. Under the influence of physical exercises, changes in the body may occur. Therefore, you need to consult a doctor.

Medical supervision of students is carried out in all organizations of physical education. The doctor identifies changes in human body. He provides data on positive or negative impacts of physical exercises, changes or improves methods of physical education.

The principle of health-improving orientation of the physical education system involves the daily creative collaboration of doctors, teachers and practitioners. If a person engaged in physical education worsens his health, and the doctor confirms this, he should not play sports intensively.

The doctor and the teacher have to anticipate possible consequences.

Thus, the meaning of this principle is to strengthen and improve human health. This principle implies that:

- wellness value is an essential criterion for physical education;

- it is necessary to plan and regulate training loads depending on gender, age and level of training;

- it is necessary to ensure regularity and unity of medical and pedagogical control;

- it is necessary to use healing forces and hygiene factors.

\section{CONCLUSION}

The main purpose of the general principles of physical education is as follows:
1. to create the most favorable conditions and opportunities for solving the problems of physical education;

2. unite the general orientation of physical education (comprehensiveness, applicability, recovery);

3. determine paths providing positive results of physical education, and implement them into practice.

Physical education and sports are transforming. They transform people from clumsy to agile; from slow to fast; from weak to strong; from fatigue to hardy; from painful to healthy [11]. Thanks to good physical training, new complex production professions are mastered faster. Physical culture and sports develop such intellectual processes as attention, the accuracy of perception, memorization, reproduction, imagination, thinking, and improve mental performance. Healthy, hardened, physically developed students successfully learn educational material, get tired less and do not miss classes due to colds. Physical education is the most important means of developing a personality. Physical education has a multifaceted effect on consciousness, will, character traits. It helps to develop moral beliefs, habits, tastes and other aspects of personality that characterize the spiritual world. Physical education and sports are seen as an integral part of education and culture. They develop abilities, willpower, moral values and self-discipline of each person as a fully integrated member of society. They contribute to the preservation and strengthening of mental and physical health, ensure full leisure, and help a person to overcome shortcomings of stressful life. At the community level, they develop social qualities, form social relations and contribute to the fair play, which is vital for sport and social life.

Physical education as a general term is associated with sociocultural, educational and social values, psychosocial qualities, socialization, inclusion, moral standards of behavior, cognitive and physical development, well-being, healthy nutrition, and other benefits derived from regular physical activities. Thus, education in general and physical education in particular should meet the needs of optimal development of personality abilities and provide opportunities for selfrealization and social interactions that are fundamental for society.

\section{References}

[1] A.R. Milian, V.R. Aguilar and M.G. Pairol, "The preparation of the teacher of physical culture in health and prevention: a way for the direction of the training of the graduate of the degree in education" Universidad y Sociedad, vol. 9, no. 3, pp. 173-176, 2017.

[2] O. Voitovska and S. Tolochko, "Physical education teachers" perspectives in a changing world: from future studies to new physical culture," Philosophy and Cosmology, vol. 20, pp. 139-145, 2018. DOI: 10.29202/phil-cosm/20/13

[3] L.Z. Samigullina, "Some Aspects of Cognitive and Ideographic Characteristics as a Means of Professional Terminological System Description," European Research Studies, vol. 18 iss. 4, p.197, 2015.

[4] A.Y. Polyakov, "Full-fledged level of physical training of a specialist is an integral part of stability of a work process," SHS Web of Conferences, vol. 50, pp. 1-3, April 2018 (CILDIAH-2018, 2018) DOI: $10.1051 /$ shsconf $/ 20185001218$

[5] A. B.-Revilla, E. S.-Jimenez, "The scientific research in the formation of the professional of the Physical Culture" Arrancada, vol. 17, No. 32 , pp. 202-214, 2017 
[6] G. Li, "Analysis on the conceptual innovation of sports culture in international communication based on the values of physical education," AgroFOOD Industry Hi-tech, vol. 28, no. 3, pp. 3486-3488, 2017.

[7] L.M. Lara, E. Rich, "The studies of physical culture at the University of Bath, United Kingdom: Dimensions of an approach that goes way beyond physicality" Movimento, vol. 23, No. 4, pp. 1311-1324, 2017 DOI: $10.22456 / 1982-8918.74326$

[8] E.R. Vasilyeva, A.R. Nurutdinova, "The academic model of managing integration processes: study case of the multicultural educational space," SHS Web of Conferences vol. 50, pp. 1-3, April 2018 (CILDIAH-2018, 2018) DOI: 10.1051/shsconf/20185001223.

[9] A.Z. Ibatova, N.V. Ippolitova, S.K. Mukhametgaliyeva, A.E. Rodionova, Kh.N. Yagafarova and L.N. Ikonnikova, "Lifelong
Professional Education in the Russian Federation: Personal Aspect,' International Journal of Environmental and Science Education, vol. 11, no. 16, pp. 9426-9436, 2016

[10] O.V. Danilova, "Peculiarities of Forming General Cultural Competences in Students of Institutions of Higher Technical Education by Means of Interdisciplinary Integration," SHS Web of Conferences vol. 50, pp. 1-5, April 2018 (CILDIAH-2018, 2018) DOI: $10.1051 /$ shsconf/20185001216

[11] E.A. Mukhtasarova, F.G. Safin, "State of modern Russian youth tolerance," European Proceedings of Social and Behavioural Sciences vol. 50, pp. 206-213, April 2018 (RPTSS 2018, p. 1464, 2018), DOI: 10.15405/epsbs.2018.12.26 